mark, Spæin, France, Greece, Italy, Luxembourg, Norway, the Netherlands, Portugal, the United Kingdom, Sweden, Switzerland and Turkey. The text of the Convention, which has now been published by the Organization for European Economic Co-operation, contains 24 articles (Pp. 67. Paris : O.E.E.C., European Nuclear Energy Agency, 1960). Its scope is limited to risks for which common law rules and practice are unsuitable, and it does not apply to nuclear incidents occurring in the territory of noncontracting States or to damage suffered in such territory. Its special regime applies only to nuclear incidents occurring at or in connexion with certain nuclear installations or in the transport of nuclear substances as defined. Risks which arise in respect of radioisotopes used for any industrial, commercial, agricultural, medical or scientific purpose are excluded, once the radioisotopes are applied for those purposes, as such risks are not exceptional : nuclear propulsion and nuclear fusion are also excluded, for different reasons. All liability for installations is channelled on to the operator of the nuclear installation where the incident occurs, while liability for incidents in transport falls either on the carrier or on the operator of the nuclear installation concerned. There are detailed provisions determining the kind of damage which will be compensated, and maximum liability in respect of any single incident has been fixed at 15 million European Monetary Agreement units of account, and rights of compensation are extinguished ten years from the date of an incident if no action has been brought before a competent court.

\section{Detection and Identification of Underground Explosions}

IN connexion with the work of the conference on nuclear test control at Geneva, the Government recently announced its intention to carry out a programme of seismic research bearing on the detection and identification of underground nuclear explosions. This programme is now being planned in detail by the U.K. Atomic Energy Authority and suitable areas for the siting of seismic measuring instruments are being investigated. The research programme will involve the firing of conventional explosive charges, but no nuclear explosives will be used. Some of the firings will probably take place in disused mines and quarries: others may take the form of charges dropped at selected points in the Channel from naval vessels. An operational centre for seismic work is being established at a converted country house a few miles from Aldermaston.

\section{The Field Studies Council}

A WIDE range of courses dealing with many topics has been arranged by the Field Studies Council for 1961. At certain periods, normally March-Whitsun, there is great pressure on accommodation at the Centres and priority is given to members.

The Easter courses for schools are now designed for second-and third-year sixth-form pupils only. For pupils in secondary modern schools, a number of countryside courses have been arranged. The programmes again include a choice of courses specially designed for teachers in primary, secondary modern and grammar schools. At all times, even when courses have been arranged, places are kept for artists, amateur naturalists and other individuals or groups who wish to organize their own programme or to pursue studies independently, or in a less formal way than is suggested by the word 'course'. The Council has at its disposal a small bursary fund which is available to reduce the fee charged in individual cases of merit where grant-aid is needed but is not obtainable. Among the more unusual courses is that at Dale Fort for teachers dealing with marine biology and oceanography as well as "Man in Pembroke. shire", a course in historical geography. At Flatford Mill a course is to be run for amateur entomologists introducing them to field techniques in insect ecology. Juniper Hall has a course on slugs and snails, while Malham Tarn has a special course on karstic landforms as well as one on spider ecology. Students of geomorphology will find a special course at Preston Montford, while Slapton Ley provides an introduction to field archæology. Deteils of these, as well as the more routine, courses may be obtained from the Publicity Secretary, Field Studies Council, Ravensmead, Keston, Kent.

\section{Biology, Psychology and Belief}

THE fourteenth lecture in memory of Sir Arthur Eddington was delivered in Cambridge on November 3 by Dr. W. H. Thorpe. Dealing with the relationships between the biological sciences and religious belief, Thorpe's lecture takes a rightful place among the more outstanding of its predecessors. To this lecture Thorpe has brought an honesty of purpose which should be of considerable help to biologists confronted with difficulties in reaching some genieral system of faith. There is also a clarity of thinking which is concerned never to confuse but to paint a world of the spirit as revealed to Thorpe. That man is a biological, as well as a spiritual, organism is well brought out, as is the conviction that no system of faith or belief has any ultimate prospect of securing the loyal and lasting adherence of educated men in the twentieth and later centuries unless it is firmly rooted in biological fact. The lecture has now been published as a booklet and should appeal to readers of all disciplines concerned with the nature of spiritual belief (Pp. 60. Cambridge : At the University Press, 1960. 4s. 6d.).

\section{Rock Shelters of the Lower Murray River}

A RECENT issue of the Proceedings of the Royal Society of Victoria contains an interesting account of an excavation undertaken at Fromm's Landing on the Lower Murray River under the leadership of D. J. Mulvaney, of the University of Melbourne (New Series, 72, Pt. 2. Victoria : The Royal Society, 1960). A rock-shelter, facing east and well suited for habitation, was explored and no less than ten different levels determined. Not enough attention has been paid by prehistorians to recent work in Australia. Maybe the finds in various regions of Africa have too exclusively engrossed their attention. Australian Stone-Age sites have been dismissed as early native. The carbon-14 method of dating has many pitfalls and cannot always be entirely relied on unless many samples from a culture-level (and not all from the same site) have been examined. But the chanees of reasonable accuracy are increasing as workers in the field are learning what precautions must be taken in procuring samples, and in the laboratory new techniques are being developed. The carbon-14 results for the lower levels at Fromm's Landing suggest a date some 4,000 years ago and one which therefore falls well within most prehistorians' periods. 